\title{
Yakemys multiporcata n. g. n. sp., a Large Macrobaenid Turtle from the Basal Cretaceous of Thailand, with a Review of the Turtle Fauna from the Phu Kradung Formation and Its Stratigraphical Implications
}

Haiyan Tong ${ }^{1,2, *}$, Phornphen Chanthasit ${ }^{3}$, Wilailuck Naksri ${ }^{4}$, Pitaksit Ditbanjong ${ }^{5}$, Suravech Suteethorn ${ }^{1}$ (D), Eric Buffetaut ${ }^{1,6}{ }^{\mathbb{D}}$, Varavudh Suteethorn ${ }^{1}$, Kamonlak Wongko ${ }^{7}$, Uthumporn Deesri ${ }^{1}$ and Julien Claude ${ }^{8}$

1 Palaeontological Research and Education Centre, Mahasarakham University, Kantarawichai, Maha Sarakham 44150, Thailand; suteethorn@yahoo.com (S.S.); eric.buffetaut@sfr.fr (E.B.); suteethorn@hotmail.com (V.S.); uthumporn_deesri@yahoo.com (U.D.)

2 Key Laboratory of Vertebrate Evolution and Human Origins, Institute of Vertebrate Paleontology and Paleoanthropology, Chinese Academy of Sciences, Beijing 100044, China

3 Sirindhorn Museum, Department of Mineral Resources, Sahatsakhan, Kalasin 46140, Thailand; aom025@gmail.com

4 Northeastern Research Institute of Petrified Wood and Mineral Resources, and Biology Program, Faculty of Science and Technology, Nakhon Ratchasima Rajabhat University,

check for updates

Citation: Tong, H.; Chanthasit, P.; Naksri, W.; Ditbanjong, P.; Suteethorn, S.; Buffetaut, E.; Suteethorn, V.; Wongko, K.; Deesri, U.; Claude, J. Yakemys multiporcata n. g. n. sp., a Large Macrobaenid Turtle from the Basal Cretaceous of Thailand, with a Review of the Turtle Fauna from the Phu Kradung Formation and Its Stratigraphical Implications. Diversity 2021, 13, 630. https://doi.org/ $10.3390 / \mathrm{d} 13120630$

Academic Editor: Michel Baguette

Received: 11 November 2021 Accepted: 27 November 2021 Published: 30 November 2021

Publisher's Note: MDPI stays neutral with regard to jurisdictional claims in published maps and institutional affiliations.

Copyright: (c) 2021 by the authors Licensee MDPI, Basel, Switzerland. This article is an open access article distributed under the terms and conditions of the Creative Commons Attribution (CC BY) license (https:// creativecommons.org/licenses/by/ $4.0 /)$.
Nakhon Ratchasima 30000, Thailand; nwilailuck@gmail.com

5 Department of Geotechnology, Faculty of Technology, Khon Kaen University, Khon Kaen 40002, Thailand; pitadi@kku.ac.th

6 CNRS (UMR 8538), Laboratoire de Géologie de lEcole Normale Supérieure, PSL Research University, 24 rue Lhomond, CEDEX 05, 75231 Paris, France

7 Mineral Resources Office Region 1, 414 Moo 3 Sala Subdistrict, Ko Kha District, Lampang 52130, Thailand; uree40@yahoo.com

8 Institut des Sciences de lEvolution de Montpellier, CNRS/UM/IRD/EPHE, 2 Place Eugène Bataillon, cc64, CEDEX 05, 34095 Montpellier, France; julien.claude@umontpellier.fr

* Correspondence: htong09@yahoo.fr

\begin{abstract}
Yakemys multiporcata n. g. n. sp. is described on the basis of shell elements from the upper part of the Phu Kradung Formation (basal Cretaceous), Khorat Plateau, NE Thailand and assigned to Macrobaenidae. The new taxon is unusually large for an early macrobaenid (with an estimated carapace length about $70 \mathrm{~cm}$ ) and is characterized by a large, rounded, low shell, the presence of a midline keel and numerous additional strong ridges on the carapace, the anterolateral margin upturned to form a gutter, posterolateral peripherals mesiolaterally expanded, narrow vertebrals, the vertebral 4 triangular and narrowed posteriorly, a greatly reduced plastron with a short bridge, an oval and elongate entoplastron with reduced ventral exposure, and strip-shaped epiplastra. The discovery of a macrobaenid turtle provides further support for an Early Cretaceous age for the upper part of the Phu Kradung Formation.
\end{abstract}

Keywords: Testudines; Macrobaenidae; Yakemys multiporcata; Phu Kradung Formation; Early Cretaceous; Khorat Plateau; Thailand

\section{Introduction}

During the Late Jurassic and the Early Cretaceous, the turtle fauna of eastern and Southeast Asia showed a clear endemism. Four groups of turtles have been identified from these regions: Xinjiangchelyidae, Sichuanchelyidae, Macrobaenidae/Sinemydidae, and stem Trionychoidae [1-5]. While Sichuanchelyidae is considered as a primitive group, the three other groups are assigned to Pan-Cryptodira and considered as groups from which modern cryptodiran families originated [4,6]. Macrobaenidae/Sinemydidae (referred to later in the text as Macrobaenidae), in particular, are potentially important as no 
consensus has been reached regarding their phylogenetic position nor their content. In addition, the overlap in terms of taxonomic content has been erratic in the literature [7]. This group is, however, important because it is found as a close relative of either Cryptodira [4] or modern turtles (crown Testudines). Documenting its fossil record can thus help to understand broad relationships, and phylogenetic history related to major splits in modern groups.

Macrobaenidae have been principally documented from Central Asia and North China $[1,8,9]$. The group dispersed to North America during the Late Cretaceous, and their remains have also been reported from the Lower Cretaceous and Paleocene of Europe [10-12]. In Asia, these freshwater turtles flourished during the Early Cretaceous; they are particularly well represented in the famous Jehol Biota. As part of the Jehol biota sensu lato, macrobaenid remains have also been reported from South Korea [13]. Macrobaenid remains have been reported from the Early Cretaceous Tetori Group, Japan [14-17], but the detailed systematic study is still outstanding. In this paper, we report on the first macrobaenid turtle from SE Asia. The material has been collected from three localities in the upper part of the Phu Kradung Formation (basal Cretaceous) of northeastern Thailand. The specimens studied herein are housed at the Sirindhorn Museum (SM), Kalasin and the Palaeontological Research and Education Centre (PRC), Mahasarakham University, Thailand. In addition to the description of a new taxon, this paper also aims at clarifying the systematics and nomenclature of Macrobaenidae and Sinemydidae. The turtle fauna from the Phu Kradung Formation is assessed and the age of that Formation is discussed.

\section{Geological Setting}

The new fossil turtle site Ban Huai Yang (บ้านห้วยยาง) is located on the western slope of Phu Bak Kom hill, southwestern part of Phu Phan Range, Tambon (sub-District) Nong Chang, Amphoe (District) Sam Chai, Changwat (Province) Kalasin, NE Thailand (Figure 1). It is about 18 kilometers northwest of the well-known Late Jurassic Phu Noi locality where the xinjiangchelyid turtles Phunoichelys thirakhupti and Kalasinemys prasarttongosothi were found $[18,19]$. Turtle shell fragments have been collected in a small creek from the weathering of maroon, micaceous mudstones. The turtle bearing-bed overlies the reddish micaceous mudstones interbedded with thin to medium bedded sandstones. Silcrete and petrified wood were also found below the turtle-bearing layer. The turtle layer is overlain by greyish medium to very thick bedded sandstones, calcareous siltstones, and thin bedded conglomerates in ascending order of the sequence. It is also worth noting that the typical pale yellow to white sandstone of the Phra Wihan Formation caps the top of the stratigraphic succession at Phu Bak Kom hill, less than 80 meters above the turtle site. Although the 1:50,000 geological map of the area places the turtle locality in the Phra Wihan Formation [20], the sedimentology and stratigraphy rather suggest that the turtle-bearing layer is actually part of the upper part of Phu Kradung Formation of the Khorat Group.

The Phu Kradung Formation, deposited in a fluvial system, is about $1000 \mathrm{~m}$ in thickness at the type locality [21-24]. Its precise age is difficult to define, as the depositional environment lacks volcanic ash. However, studies on palynology [25] and detrital zircon [26] indicated that the Phu Kradung Formation ranges from Late Jurassic to Early Cretaceous. Located in the upper part of the Phu Kradung Formation, the new turtle site is likely basal Cretaceous in age. This is also supported by its paleontological content, in particular the turtle assemblage which includes Basilochelys sp. and the new macrobaenid described in the present study, comparable with other turtle assemblages known from the upper part of the formation (Kham Phok, Dan Luang, and Phu Phan Kham), but distinct from that from the Late Jurassic Phu Noi site (see discussion in Turtles from the Phu Kradung Formation and Their Implications for the Age of the Formation section below). 


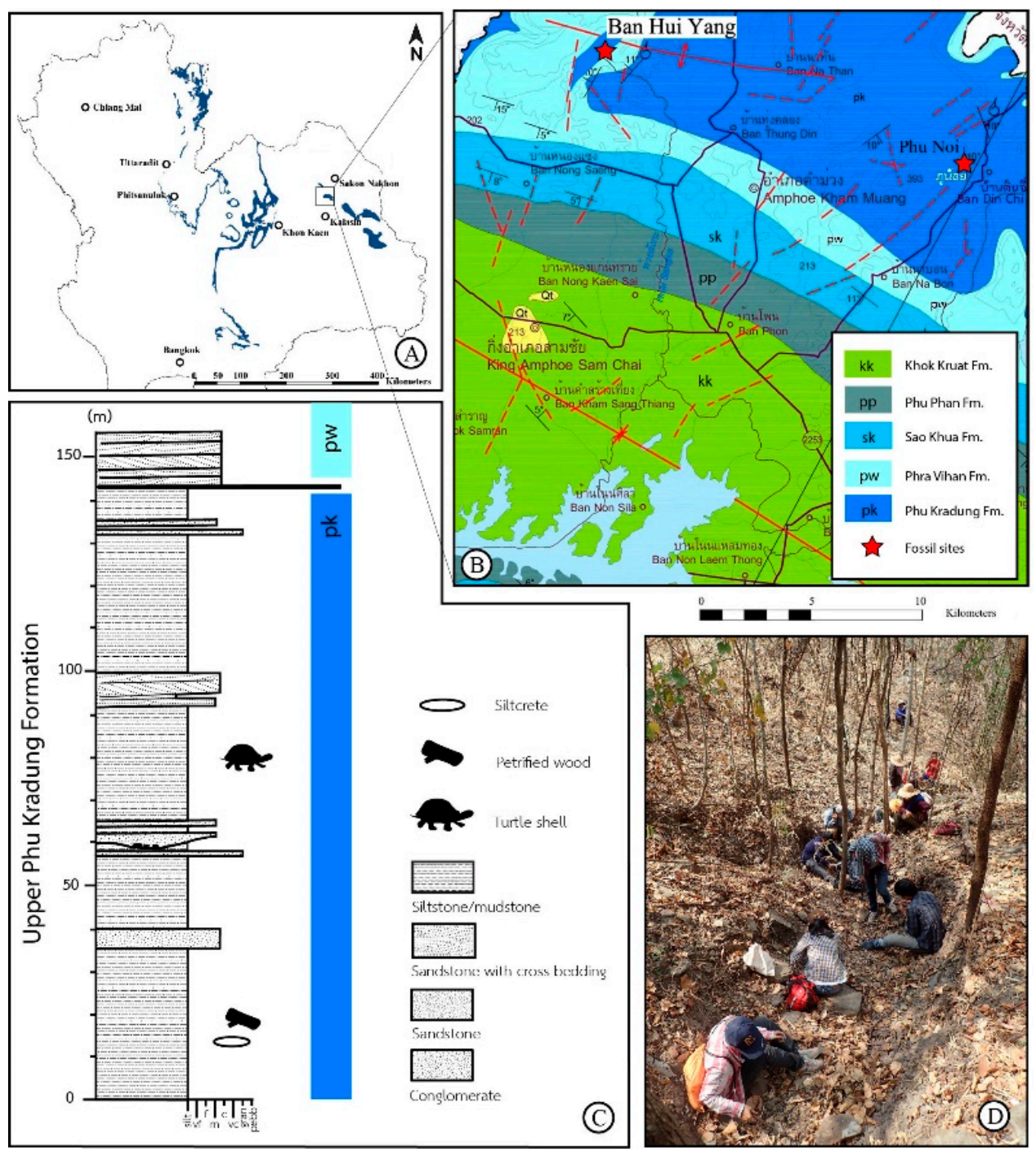

Figure 1. (A), Map of northern Thailand showing location of Sam Chai area, and outcrops of the Phu Kradung Formation; (B): Geological map of Sam Chai area (modified from [20]; (C): Stratigraphical column of Ban Hui Yang site; (D): Field work.

\section{Systematic Paleontology}

Testudines Linnaeus, 1758

Cryptodira Cope, 1868

Macrobaenidae Sukhanov, 1964

Yakemys multiporcata n. gen. n. sp.

(Figures 2 and 3)

Etymology Genus name from Yak, giant in Thai (ขักษ์); species name from Latin multi: multiple; porcata: from Latin porca, ridge.

Holotype: SM KS39, a partial shell; including incomplete neurals 4-5 and complete neurals $6-8$, incomplete suprapygals $1-2$, complete pygal; incomplete right costals $2-4$ and left costal 5-6, left peripheral 2-11 (only the 8th and 10-11th are complete), and incomplete right peripherals 3-5 and 10-11; anterior lobe of the plastron including a small fragment of left epiplastron, complete entoplastron, part of right and left hyoplastra, and incomplete right hypoplastron, with both axillary and left inguinal buttresses. All belong to the same individual (Figures 2 and $3 \mathrm{~A}, \mathrm{~B}$ ). 


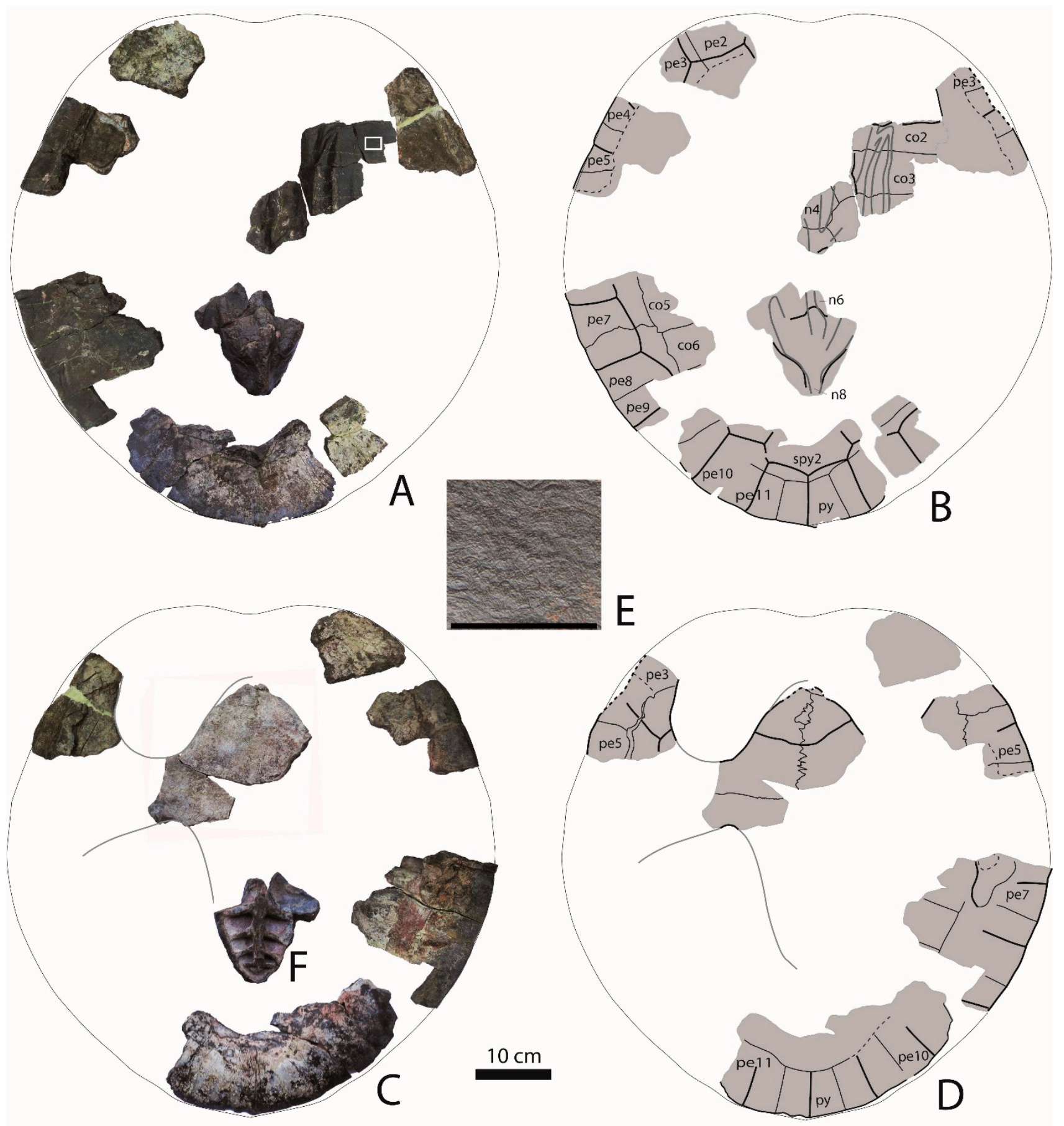

Figure 2. Yakemys multiporcata n. g. n. sp. from the upper part of the Phu Kradung Formation (basal Cretaceous) of Khorat Plateau, NE Thailand. Holotype (SM KS39) from Ban Hui Yang locality, Sam Chai District, Kalasin Province. (A,B) Carapace in dorsal view; (C,D) shell in ventral view; (E) detail of ornamentation of the carapace surface (on costal 2, indicated by a white rectangle on $\mathbf{A}$ ), and (F) neural 6-8 with adjacent costal fragments in ventral view. Scale bar $=10 \mathrm{~cm}$ for (A-D,F) and $2 \mathrm{~cm}$ for (E). Abbreviations: co, costal plate; Ma, marginal scute; n, neural plate; pe, peripheral plate; py, pygal plate; spy, suprapygal plate; $\mathrm{V}$, vertebral scute. 

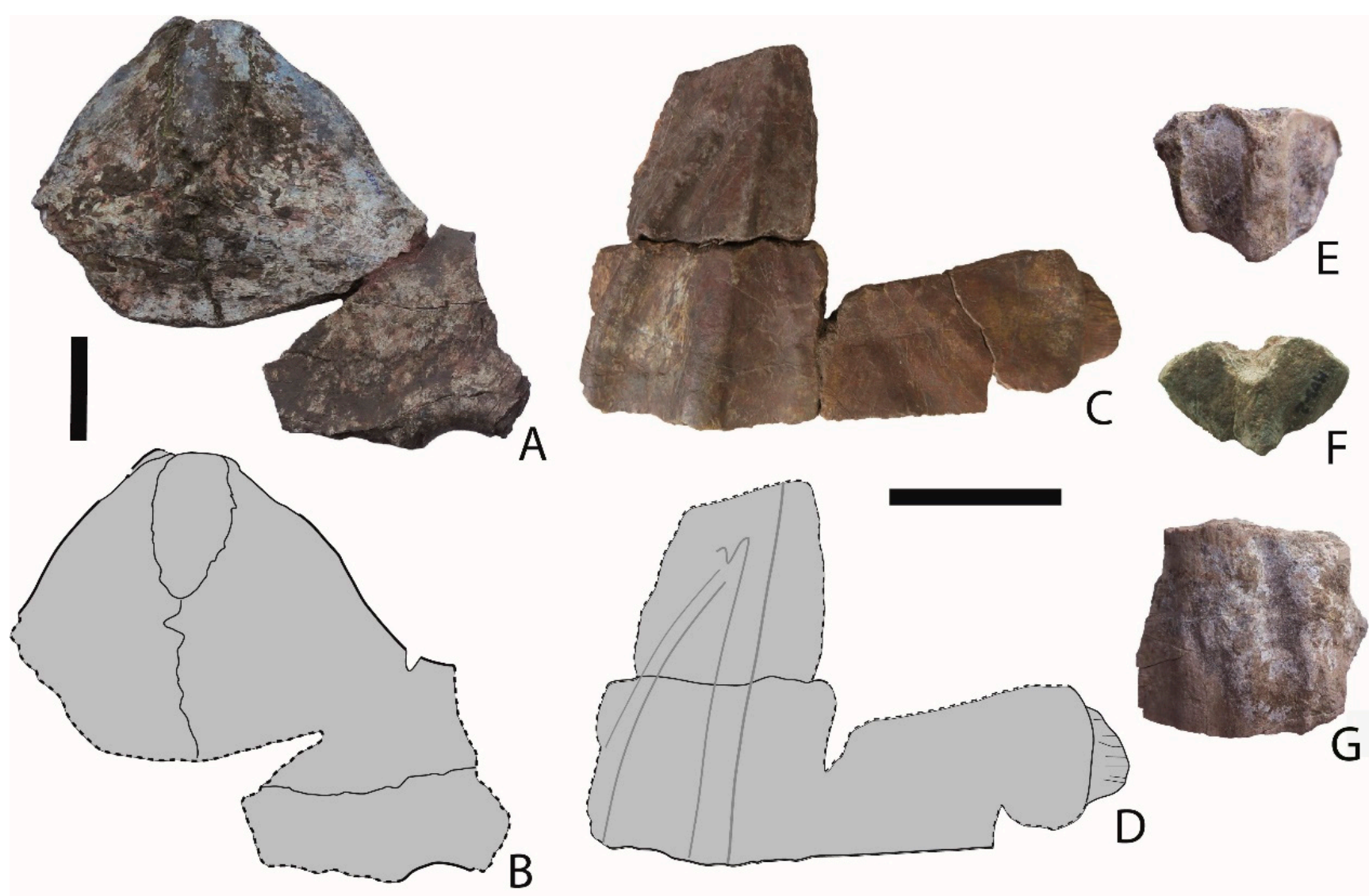

Figure 3. Yakemys multiporcata n. g. n. sp. from the upper part of the Phu Kradung Formation (basal Cretaceous) of Khorat Plateau, NE Thailand. (A,B): Holotype (SM KS39) from Ban Hui Yang locality, Sam Chai District, Kalasin Province, partial plastron in dorsal view; (C,D): two incomplete costals (PRC151) from Phu Phan Kham locality, Nong Bua Lamphu Province; (E) (PRC152), a posterior neural, (F) (SM2021-1-131), a suprapygal 1 and (G) (PRC153), a fragment of costal from Dan Luang locality, Mukdahan Province. Scale bar $=5 \mathrm{~cm}$ (vertical scale for $(\mathbf{A}, \mathbf{B})$; horizontal scale for $(\mathbf{C}-\mathbf{G})$ ).

Referred material: PRC151 (Field number PRC PK133, PK134, PK138), two incomplete costals from Phu Phan Kham locality, Non Sang, Nong Bua Lamphu Province (Figure 3C,D); PRC152, a posterior neural (Figure 3E); SM2021-1-131, a suprapygal 1 (Figure 3F); PRC153, a fragment of costal (Figure 3G), and other unnumbered shell fragments from Dan Luang locality, Mukdahan Province, Thailand; upper part of the Phu Kradung Formation, basal Cretaceous.

Type locality and horizon: Ban Hui Yang site, Amphoe (District) Sam Chai, Changwat (Province) Kalasin, NE Thailand; upper part of the Phu Kradung Formation, basal Cretaceous.

Diagnosis: A genus of Macrobaenidae of large size, with the carapace length about $70 \mathrm{~cm}$ and a combination of characters that differs from all other Macrobaenidae as follows: narrow vertebral scutes; vertebral 4 triangular and narrowed posteriorly, strong midline keel extending to the suprapygal 2, large lateral longitudinal keels on the vertebral region, and additional ridges on the pleural region; plastron reduced, with a triangular short anterior lobe, epiplastron reduced to a strip-shaped plate, entoplastron oval in dorsal view but with a much reduced ventral exposure and an extremely reduced bridge that is shorter than the anterior lobe.

Distribution: Kalasin, Nong Bua Lamphu and Mukdahan Provinces, northeastern Thailand; upper part of the Phu Kradung Formation, Lower Cretaceous. 


\subsection{Description}

\subsubsection{Holotype}

Shell surface ornamentation: The whole carapace surface is covered by a thin network of tiny furrows (see Figure 2E).

Carapace: The shell is large (estimated carapace length: about $70 \mathrm{~cm}$ ), with a rounded outline when reconstructed. The anterolateral margin of the carapace is thickened and upturned, forming a wide gutter as in xinjiangchelyids and macrobaenids. The posterior edge is sharp and slightly flared, with a small protrusion at the midline. Whether a nuchal emargination is present is unclear since the anterior margin of the carapace is missing.

The prominent feature of the carapace is the presence of numerous strong ridges on its carapace. A blunt midline keel is preserved from the neural 4 to the suprapygal 2; it is stronger on the posterior neurals. Additional large and blunt ridges are located on the vertebral and pleural regions. Originating from the midline keel at about the level of the neurals 7, a short ridge extends anteriorly and ends at the costal 6 . There is another large ridge located next to the neurals $4-5$. In addition, there is a group of smaller but well-developed ridges originating on the costal 2, posterior to the interpleural sulcus between the pleurals 1 and 2. Two of them, which are the most laterally located and more prominent, extend backward in a radiating manner to at least the costal 4.

The nuchal plate is not preserved. The neurals 4 and 5 , only partly preserved, have a hexagonal outline with short anterolateral sides. The neurals 6 to 8 are apparently complete, but the sutures are not discernible, so their shape is unclear. Judging by the position of the sacral vertebrae, at least the anterior end of the suprapygal 1 is preserved, but here, again, the suture with the neural 8 is not visible. The posterior portion of the suprapygal 2 is preserved; it is large and contacts posteriorly the pygal and the peripherals 11 . The pygal is rectangular and wider than long, with the lateral margins slightly convergent forward. Most peripherals are incomplete, except the left peripherals 8 and 10-11. The peripherals 7 to 9 are mesiolaterally expanded as in xinjiangchelyds and macrobaenids. The peripheral 8 contacts the costals 5 and 6 . The peripheral 11 is roughly square in shape.

The visceral surface of the costals is marked by low and blunt swellings extending throughout the width of the plates. The swelling is, however, narrower and less marked close to the rib head. The rib swelling on the costal 5 is stronger than on the costal 6 . The rib heads are strong. The rib heads $6-8$, firmly fused to the dorsal vertebrae, are long and directed anteromedially, and their length decreases posteriorly. The sacral ribs (dorsal ribs 9 and 10) are shorter than that of the rib 8 and directed transversely.

The scute sulci are well imprinted. The vertebral 1 is apparently wider than the vertebral 2 . The vertebrals $2-5$ are narrow. The most complete vertebral is the 4 th, it is roughly triangular in shape, with a strongly narrowed posterior end. Most marginals are restricted to the peripherals, whereas the marginals 11-12, longer than wide, are longer than the corresponding peripherals and pygal.

Plastron: The plastron is incomplete, lacking the posterior part. The anterior lobe has a triangular outline; its ventral surface is slightly concave, whereas its dorsal surface is strongly convex. The left axillary buttress is complete whereas the right one lacks the anterior end. These buttresses are long, extending anteromedially to the posterior half of the peripheral 3. The end of the inguinal buttress, preserved on the left side, remains sutured to the peripheral 7 and the anteromedial end of the peripheral 8 . As preserved on the right side, the plastron has a sutural contact with the carapace, but the suture is open. The bridge, partly preserved on the right side, is extremely short, with a length of $92 \mathrm{~mm}$, which is clearly shorter than the anterior lobe $(120 \mathrm{~mm})$.

Only a fragment of the left epiplastron is preserved, but the suture between the epiplastra and hyoplastra is preserved on both sides. The epiplastron is reduced and stripshaped, flanking against the anterolateral margin of the hyoplastron, as in macrobaenids. Although damaged, the right and left epiplastra would meet shortly anterior to the entoplastron, preventing the latter from being exposed along the anterior plastral margin. The entoplastron is an elongate oval plate as seen from above, whereas its ventral exposure 
is much reduced to a small irregular and roughly triangular element, as in some macrobaenids, such as Ordosemys liaoxiensis [27]. The hyoplastron is large, with a strongly interfingering suture with its counterpart and with the entoplastron. The hypoplastron and hyoplastron have similar contributions to the bridge length. In ventral view, the humeropectoral sulcus is located posterior to the entoplastron but far anterior to the base of the anterior lobe, it is convex posteriorly. As preserved on the right side, at least two inframarginals are present on the hyoplastron, they are restricted to the bridge region.

\subsubsection{Phu Phan Kham Specimens (PRC151)}

PRC151 consists of two incomplete costals, probably the right costals 2 and 3 . The specimen is $25 \%$ smaller than the holotype, with the length of the costal 3 at the level of the lateral ridge measuring $4.5 \mathrm{~cm}$ (instead of $6 \mathrm{~cm}$ in SM KS39); thus, the carapace length of PRC 151 is estimated at about $53 \mathrm{~cm}$.

Similar to SM KS39, the costals bear two ridges originating from the costal 2 and extending backward to at least the costal 3. Lateral to the ridges, the surface of the costal 3 is undulated. As preserved, the costal 3 bears a large free rib end laterally. The ornamentation of the outer surface is similar to that of SM KS39. No scute sulci are visible. The inner surface of both costals bears a large and blunt rib swelling.

\subsubsection{Dan Luang Specimens (PRC152, PRC153 and SM2021-1-131)}

The surface ornamentation of these specimens is similar to that of SM KS39. The posterior neural (PRC152, probably the neural 7) is a roughly hexagonal plate, wider than long, with short anterolateral sides. It bears a strong midline keel. The suprapygal 1 (SM2021-1-131) is wider than long, it bears a midline keel throughout its length. PRC153, a fragment of a costal, has an uneven outer surface and bears two longitudinal low ridges.

\subsection{Semantic and Nomenclatural Remarks}

Macrobaenidae was erected by Sukhanov [28] to place Macrobaena in a distinct family and to exclude it from Baenidae. The group content was later extended to include other genera such as Kirgizemys/Hangaiemys, Ordosemys, and Dracochelys (e.g., [1,10,29-33]. On the other hand, Sinemydidae was introduced in 1963 by Ye to include the genera Sinemys and Manchurochelys [34]. In 1976, Chkhikvadze expanded Sinemydidae to include Macrobaenidae, whereas other authors considered that Sinemydidae and Macrobaenidae should not be united [35,36]. The expanded and restricted concepts of these two groups have been followed by different authors, but no consensus has been reached concerning the family name nor their content, as well as the monophyly of this large group of turtles (see [37] for a thorough review). For some authors, Sinemydidae sensu lato is a monophyletic group [38], while other authors consider this group as a polyphyletic assemblage [39,40]. In order to stabilize the nomenclature, some authors have suggested to use a more restricted concept, the clade containing Macrobaena and excluding Sinemys forming the Macrobaenidae [7,41], while the clade containing Sinemys and excluding Macrobaena forms the Sinemydidae [37,41]. These two exclusive definitions do not allow any inclusive possibility of one clade with the other, which is problematic as the phylogenetic position of Macrobaena was never tested.

As the present paper concerns a new genus and new species of this group, and in order to test the phylogenetic relationships within the group, we chose to adopt the definitions close to those proposed by Sukhanov [28] for Macrobaenidae and by Ye [34] for Sinemydidae. We therefore consider Macrobaenidae as the smallest clade containing Macrobaena mongolica and Kirgizemys hoburensis, and adopt the definition of Ye [34] for Sinemydidae, which includes Sinemys and Manchurochelys.

\subsection{Phylogenetic Assignment}

In order to estimate the phylogenetic relationships of Yakemys multiporcata with other turtles, we performed a phylogenetic analysis using the character/taxa matrix defined 
by Joyce et al. [4], which was later modified by Pérez-García and Codrea [42] and PérezGarcía et al. [43]. We discarded the characters relative to skull scute pattern (characters 91 to 105 of Joyce et al. [4]) since the position and the homology of the cranial scutes are difficult to define among groups. Characters relative to plastral kinesis (134 to 136 of Joyce et al. [4]) have been recoded to better differentiate the hinge in terms of position and homology. Original characters 112, 113, and 244 of Joyce et al. [4] regarding carapace sculpturing which are redundant are recoded as a new single character. Character 131 of Joyce et al. [4], regarding the position of marginals relative to costals, is recoded in three new characters in order to better take into account the primary homology.

Two additional characters described in Joyce and Rollot [44] are appended and seven new characters relative to the first vertebral scute, the fifth vertebral scute, the first peripheral, and the first costal plate are added to the matrix. The resulting matrix totalizes 238 characters.

In addition to Yakemys multiporcata and the taxa scored in the analyses of Joyce et al. [4], we scored the characters for Macrobaena mongolica Tatarinov, 1959 based on Tatarinov [45] and Sukhanov and Narmandakh [46]. Several character states are rescored from our observations or based on recent revisions [2,3,42-44,47]. Forty-nine of the 238 characters are coded in Yakemys, representing about $21 \%$ of the matrix. In order to reduce the number of equal trees found in the heuristic search and to decrease a basal attraction bias with other taxa that would be underdocumented in the analyses of former authors, we dropped other taxa for which states were scored for less than 30 percent of the characters of the matrix and the terminal unit Ordosemys sp. skull from the original dataset. We used the taxon Chengyuchelys latimarginalis [2] to clarify the score of Chengyuchelys in the original matrix as it is the best-documented species of the genus. The analysis was therefore run on 106 taxa and 238 characters. The updated matrix is given in the Supplementary S1.

Parsimony analyses were performed under PAUP 4.0a169 [48] using random addition sequence and the tree bisection-reconnection branch swapping algorithm across 1000 replicates, setting the rearrangement limit to $10,000,000$. We made sure that the analyses converged well in terms of total number of trees found. Thirty-three multistate characters were ordered because they represent morphological clines. All ordered multistate characters (three or four states) were scaled so they would count a maximum of one step between two taxa (in other terms, in doing so, those characters would not have a disproportionate effect above binary and unordered characters on phylogeny estimation).

We used a molecular backbone based on the recent literature [49] to constrain the tree. After 500 replicates, the number of new equal trees remained nearly constant and a total of 17,445 equal trees of 924.99 steps were found.

The analysis recovered a phylogeny close to those of Zhou and Rabi [38] and Joyce et al. [4] with small differences (Figure 4, Supplementaries S2 and S3). Plesiochelyidae, Macrobaenidae, and Xinjiangchelyidae form a monophyletic clade which is a sister group of all modern Cryptodira. Siamochelys peninsularis, Sinaspideretes wimani, and Basilochelys macrobios are nested within Xinjiangchelyidae. Xinjiangchelyidae are the sister group of Macrobaenidae. Yakemys multiporcata is always found in the clade containing Macrobaena mongolica, but the exact content of the clade varies from one tree to another (cf. differences between the Adams and strict consensus trees), sometimes including the clade Kirgizemys hoburensis plus Judithemys sukhanovi, or Changmachelys bohlini. Furthermore, Sinemydidae sensu Ye, 1963 (which includes Sinemys and Manchurochelys) formed a monophyletic clade with Dracochelys bicuspis. As these Sinemydidae are found nested within Macrobaenidae, they should be considered as a subfamily of Macrobaenidae (Sinemydinae). The basal relationships within Macrobaenidae are not resolved in the strict consensus, whereas in the Adams consensus, Yakemys multiporcata and Macrobaena mongolica are united. 


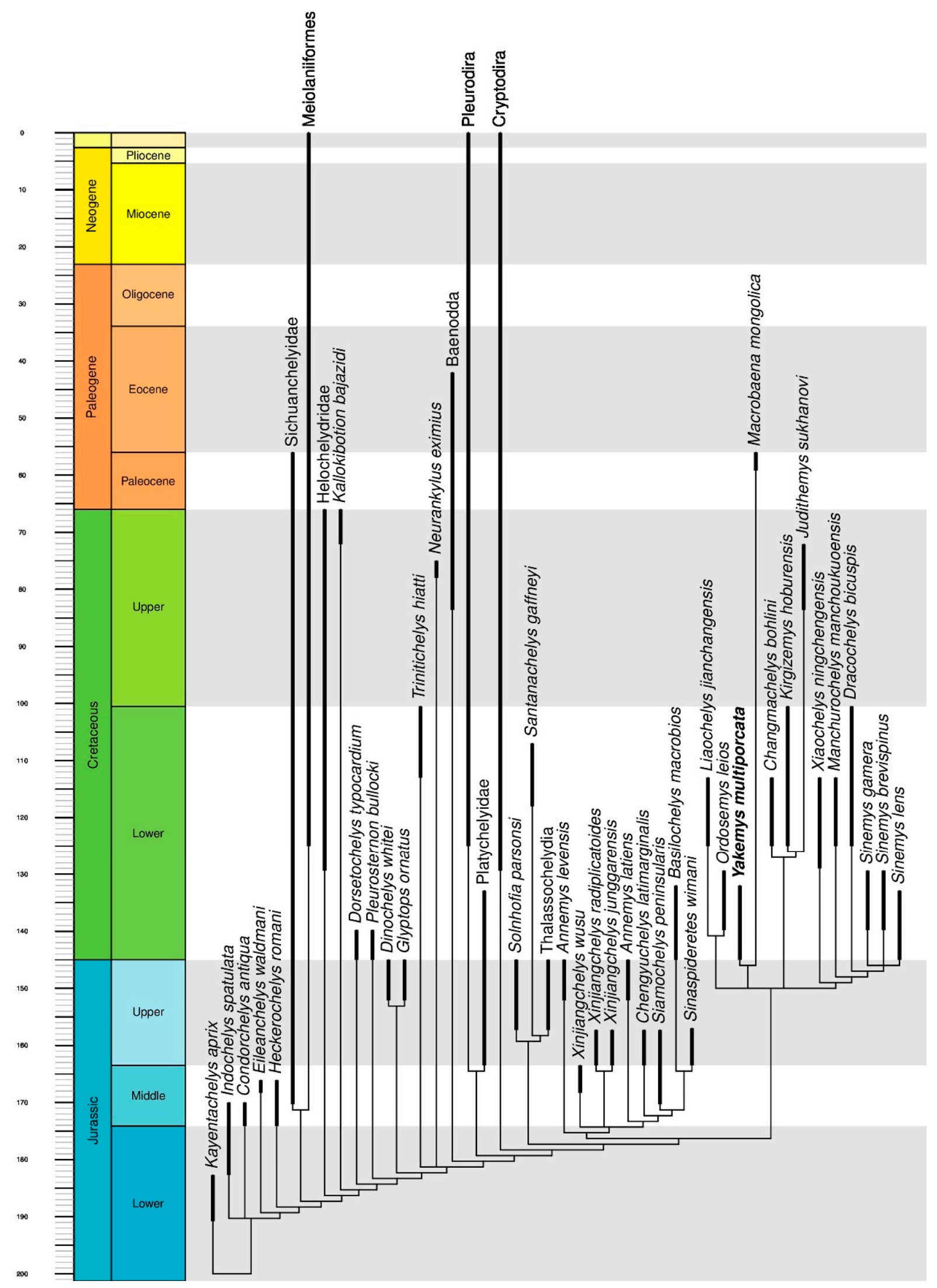

Figure 4. Simplified Adams consensus cladogram obtained from the constrained phylogenetic analysis. 
As constructed here, Macrobaenidae includes the following genera: Yakemys (this study); Manchurochelys Endo and Shikama, 1942 (Yixian Formation (Barremian-Aptian), Liaoning, China [50-53]; Kirgizemys Nessov and Khosatzky, 1973 (including Hangaiemys Sukhanov and Narmandakh, 1974; Albian of Kyrgyzstan, Barremian-Aptian of Transbaikalia, Russia, Aptian-Albian of Mongolia and Early Cretaceous of Gansu, China [29]; Dracochelys Gaffney and Ye, 1992 (Tugulu Group (Early Cretaceous), Junggar Basin, China [33,54]); Ordosemys Brinkman and Peng, 1993 (Luohandong Fm. of Inner Mongolia and Mengyin Fm. of Shandong, Yixian Fm. of Liaoning and Chengzihe Fm. of Helongjiang, China [27,30,55-58]; Liaochelys Zhou, 2010 (Jiufotang Fm. (Aptian), Liaoning, China [59]); Changmachelys Brinkman, Yuan, Ji, Li and You, 2013 (Xiagou Fm. (Aptian), Changma Basin, Gansu, China [32]; Xiaochelys Zhou and Rabi, 2015 (Yixian Fm., Inner Mongolia, China [38]; Sinemys Ye, 1963 (Luohandong Fm. and Jingchuan Fm. (Early Cretaceous) of Inner Mongolia and Mengyin Fm. of Shandong [34,37,60,61]), and Judithemys Parham and Hutchison, 2003 (Late Cretaceous to Paleocene, North America [31,62,63]). Other genera, likely belonging to the group include Hongkongochelys Ye, 1999 (Late Jurassic Shangshaximiao Fm., Sichuan Basin, China [64]); Wuguia Matzke, Maisch, Pfretzschner, Sun and Ströhr, 2004 (Hutubihe Fm. and Lianmuxin Fm., Tugulu Group (Early Cretaceous), Junggar Basin, Xinjiang, China [65-67]); Yumenemys Bohlin, 1953 (Early Cretaceous, Gansu, China [68], Jeholochelys Shao, Li, Yang and Zhou, 2018 (Jiufotan Fm. (Aptian), Liaoning, China [69]); Aurorachelys (Late Cretaceous, Canada [10]); Anatolemys (Late Cretaceous, Tadzhikistan [36]), and Tienfucheloides (Khodzhakul Formation (Cenomaian), Uzbekistan [70]). Some basal eucryptodiran turtle remains from the Early Cretaceous and Paleocene of Europe have been assigned to Macrobaenidae, including Hoyasemys and Galvechelone (Early Cretaceous, Spain) and Gallica (Paleocene, France [11,12,71]).

\subsection{Comparisons}

\subsubsection{Comparison with Sympatric Species Basilochelys macrobios}

Yakemys multiporcata shares with Basilochelys macrobios, a supposed basal trionychoid turtle from the same stratigraphical unit (upper part of the Phu Kradung Formation) of Thailand, a large size, and thickened and upturned free margin of the anterolateral peripherals forming a gutter and narrow vertebrals. However, it is distinguished from the latter in the ornamentation on the shell surface, in having the midline and lateral keels on the carapace, a triangular vertebral 4 , a reduced plastron with a triangular anterior lobe, reduced epiplastra and entoplastron, a very short bridge, and a humeropectoral sulcus located far anterior to the base of the anterior lobe and posterior to the entoplastron. In B. macrobios, the keels are absent on the carapace, the vertebral 4 is quadrangular, the anterior lobe is large, and the plastron is unreduced with a longer bridge, and a large and wide oval entoplastron [72].

\subsubsection{General Comparisons}

Yakemys multiporcata shares with xinjiangchelyids and macrobaenids the thickened and upturned anterolateral margin of the carapace forming a gutter and the mesiolaterally expanded posterolateral peripherals [2,73]. Although incomplete, the turtle shell from Ban Hui Yang (SM KS39) shows important macrobaenid features, notably a reduced plastron. The reduction of the plastron implies a small triangular anterior lobe and a short bridge, with the epiplastron reduced to a strip-shaped element located along the anterolateral plastral margin and a short epiplastral midline contact anterior to the entoplastron. These features are reminiscent of macrobaenids such as Ordosemys liaoxiensis, O. brinkmania, and Kirgizemys hubuensis from the Early Cretaceous of northern China and Mongolia, and Judithemys sukhanovi from the Late Cretaceous of North America [27,29,30,62]. In comparison, xinjiangchelyids have a more developed plastron, with larger anterior and posterior lobes, a wider anterior end of the plastron, a longer bridge, less reduced epiplastra with the long axis directed transversely, and a longer midline contact with its counterpart [2,7]. Sinemys spp. and Manchurochelys manchoukuoensis also have a reduced, cruci- 
form plastron, but in this group, the epiplastra are located at the front end of the plastron and are completely separated from the hyoplastra by a strip-shaped, and wider than long, entoplastron $[37,53,60]$. Moreover, the entoplastron of SM KS39 is oval in shape and elongate anteroposteriorly in dorsal view, but in the ventral view, its outer surface is reduced to an irregular triangle with strong interfingering sutures with the hyoplastra. This is reminiscent of the condition in the macrobaenid Ordosemys liaoxiensis [27], whereas the entoplastron in xinjiangchelyids has a more regular oval ventral exposure $[2,7,40,74]$.

Yakemys multiporcata is distinct from all other macrobaenids in having the prominent keels on the carapace, very narrow vertebral scutes, a triangular vertebral 4 , and an extremely short bridge. The narrow vertebrals resemble those of Anatolemys maximus, Aurorachelys gaffneyi, Kirgizemys spp. Changmachelys bohlini, and Manchurochelys manchoukuoensis, whereas in Dracochelys bicuspis, Jeholochelys lingyuanensis, Liaochelys jianchangensis, Ordosemys spp., and Xiaochelys ninchengensis, the vertebrals are wider. The triangular vertebral 4, as seen in SM KS39, is unique among macrobaenids. Although a reduced cruciformshaped plastron with a short bridge is characteristic of Macrobaenidae relative to Xinjiangchelyidae, the bridge in Yakemys multiporcata is unusually short, which is shorter than the anterior lobe. In comparison, in most macrobaenids (e.g., Ordosemys liaoxiensis and O. brinkmania, Kigizemys hoburensis and K. exaratus, and Judithemys russelli), the bridge is slightly longer than the anterior lobe, whereas Dracochelys bicuspis, Aurorachelys gaffneyi, and Judithemys shukhanovi have the bridge and the anterior lobe of similar length. Only Judithemys backmani and Macrobaena mongolica have the bridge shorter than the anterior lobe. Although the carapace of Tienfucheloides undatus Nessov, 1978 from the Late Cretaceous of Uzbekistan also bears strong ridges [70,75], the ridges are more numerous and present not only on the pleural region but also on the marginal region. Moreover, it is distinguished from Yakemys multiporcata by the heart-shaped carapace, the wider and shorter vertebral scutes, and a trapezoidal vertebral 4. Hoyasemys jimenezi and Galvechelone lopezmartinezae from the Early Cretaceous of Spain are distinguished from Yakemys multiporcata in having wider than long vertebrals [12,71]. Gallica lapparentiana from the Paleocene of France differs in the absence of keels on the carapace, and a less reduced plastron including longer bridge, and larger epiplastra and entoplastron [11].

\section{Size of Macrobaenid Turtles}

The size of Yakemys multiporcata is unusually large among the Early Cretaceous Macrobaenidae (see Table 1). As noticed by Parham and Hutchison [62], the size of macrobaenids from the Early Cretaceous is relatively small; most of them have a carapace length not exceeding $30 \mathrm{~cm}$. The largest is probably Changmachelys bohlini from the Lower Cretaceous Xiagou Formation, Gansu, China, with a carapace length of $35 \mathrm{~cm}$ [32]. Some species of the genus Kirgizemys also have a carapace length reaching $35 \mathrm{~cm}$ [29]. Another relatively large Early Cretaceous macrobaenid is Dracochelys bipiscus. Although a reported shell measures $30 \mathrm{~cm}$ in length [54], the holotype of the species, a large isolated skull which is $9 \mathrm{~cm}$ long would correspond to a carapace length of about $36 \mathrm{~cm}$ when compared with the holotype of Changmachelys bohlini with the complete skull and shell preserved. The size of macrobaenid turtles apparently tends to increase during the course of evolution, with the Late Cretaceous and Paleocene macrobaenids reaching a much larger size by comparison with the Early Cretaceous species. The largest are Anatolemys maximus from the Late Cretaceous of Tadzhikistan and Judithemys backmani from the Paleocene Clarkforkian of North America, with a carapace length reaching $70 \mathrm{~cm}[31,36]$, comparable to SM KS39. Therefore, the large size of Yakemys multiporcata appears to be an exception for the Early Cretaceous Macrobaenidae. It is noteworthy that another turtle from the upper part of the Phu Kradung Formation, Basilochelys macrobios (a supposed Trionychoidae), is even larger, with a carapace length reaching $90 \mathrm{~cm}$ [72]. The reason for the occurrence of large turtles at the beginning of the Cretaceous in SE Asia is unclear; it may be related to the climate or to paleogeography. 
Table 1. Size of Macrobaenidae.

\begin{tabular}{|c|c|c|c|c|}
\hline Taxon & Location & Formation and Age & Carapace Length (in $\mathrm{cm}$.) & References \\
\hline \multirow[t]{2}{*}{ Ordosemys leios } & $\begin{array}{l}\text { Ordos Basin, Inner } \\
\text { Mongolia, China }\end{array}$ & $\begin{array}{l}\text { Luohandong Fm. } \\
\text { Early Cretaceous }\end{array}$ & 28 & {$[55]$} \\
\hline & $\begin{array}{l}\text { Xintai, Shandong, } \\
\text { China }\end{array}$ & $\begin{array}{c}\text { Mengyin Fm. } \\
\text { Early Cretaceous } \\
\text { (Berriasian-Valanginian) }\end{array}$ & 26.3 & [57] \\
\hline O. liaoxiensis & $\begin{array}{l}\text { Western Liaoning, } \\
\text { China }\end{array}$ & $\begin{array}{c}\text { Yixian Fm. } \\
\text { Early Cretaceous } \\
\text { (Barremian-Aptian) }\end{array}$ & 21.3 & [27] \\
\hline O. brinkmania & $\begin{array}{l}\text { Junggar Basin, } \\
\text { Xinjiang, China }\end{array}$ & $\begin{array}{l}\text { Tugulu Group } \\
\text { Early Cretaceous }\end{array}$ & 23 & {$[30]$} \\
\hline O. donghai & $\begin{array}{l}\text { Jixi, Helongjiang, } \\
\text { China }\end{array}$ & $\begin{array}{l}\text { Chengzihe Fm. } \\
\text { Early Cretaceous } \\
\text { (Aptian-Albian) }\end{array}$ & 23 & [56] \\
\hline $\begin{array}{l}\text { Manchurochelys } \\
\text { manchoukuoensis }\end{array}$ & $\begin{array}{l}\text { Western Liaoning, } \\
\text { China }\end{array}$ & $\begin{array}{c}\text { Yixian Fm. } \\
\text { Early Cretaceous } \\
\text { (Barremian-Aptian) }\end{array}$ & 17 & {$[51]$} \\
\hline $\begin{array}{l}\text { Liaochelys } \\
\text { jianchangensis }\end{array}$ & $\begin{array}{l}\text { Jianchang, Western } \\
\text { Liaoning, China }\end{array}$ & $\begin{array}{l}\text { Jiufotang Fm. } \\
\text { Early Cretaceous (Aptian) }\end{array}$ & 17.2 & [59] \\
\hline $\begin{array}{c}\text { Xiaochelys } \\
\text { ningchengensis }\end{array}$ & $\begin{array}{l}\text { Chifeng, Inner } \\
\text { Mongolia, China }\end{array}$ & $\begin{array}{c}\text { Yixian Fm. } \\
\text { Early Cretaceous } \\
\text { (Barremian-Aptian) }\end{array}$ & 13 & [38] \\
\hline $\begin{array}{l}\text { Jeholochelys } \\
\text { lingyuanensis }\end{array}$ & $\begin{array}{l}\text { Lingyuan, Western } \\
\text { Liaoning, China }\end{array}$ & $\begin{array}{l}\text { Jiufotang Fm. } \\
\text { Early Cretaceous (Aptian) }\end{array}$ & 20 & [69] \\
\hline Changmachelys bohlini & $\begin{array}{l}\text { Changma Basin, } \\
\text { Gansu, China }\end{array}$ & $\begin{array}{c}\text { Xiagou Fm. } \\
\text { Early Cretaceous (Aptian) }\end{array}$ & 35 & [32] \\
\hline Dracochelys bicuspis & $\begin{array}{l}\text { Junggar Basin, } \\
\text { Xinjiang, China }\end{array}$ & $\begin{array}{l}\text { Tugulu Group } \\
\text { Early Cretaceous }\end{array}$ & 30 & {$[54]$} \\
\hline Wuguia hutubeiensis & $\begin{array}{l}\text { Junggar Basin, } \\
\text { Xinjiang, China }\end{array}$ & $\begin{array}{c}\text { Hutubihe Fm. } \\
\text { Early Cretaceous } \\
\text { (Hauterivian-Barremian) }\end{array}$ & 13.7 & {$[65]$} \\
\hline W. efremovi & $\begin{array}{l}\text { Junggar Basin, } \\
\text { Xinjiang, China }\end{array}$ & $\begin{array}{c}\text { Lianmuxin Fm. (Tugulu } \\
\text { Group) } \\
\text { Early Cretaceous } \\
\text { (Aptian-Albian?) }\end{array}$ & 15 & [67] \\
\hline Kirgizemys spp. & $\begin{array}{l}\text { Kyrgyzstan, Russia, } \\
\text { Mongolia, China }\end{array}$ & Early Cretaceous & $25-35$ & [29] \\
\hline Anatolemys maximus & Fergana, Tadzhikistan & $\begin{array}{c}\text { Late Cretaceous } \\
\text { (Turonian-Santonian) }\end{array}$ & 70 & {$[36]$} \\
\hline Macrobaena mongolica & Mongolia & Late Paleocene & 55 & {$[45]$} \\
\hline Aurorachelys gaffneyi & $\begin{array}{c}\text { Axel Heiberg Island, } \\
\text { Canada }\end{array}$ & $\begin{array}{c}\text { Late Cretaceous } \\
\text { (Turonian-Coniacian) }\end{array}$ & 36 & [10] \\
\hline Judithemys sukhanovi & $\begin{array}{l}\text { Dinosaur Provincial } \\
\text { Park, Alberta, Canada }\end{array}$ & $\begin{array}{l}\text { Dinosaur Park Fm. } \\
\text { Late Cretaceous } \\
\text { (Campanian) }\end{array}$ & 40 & [62] \\
\hline
\end{tabular}


Table 1. Cont.

\begin{tabular}{|c|c|c|c|c|}
\hline Taxon & Location & Formation and Age & Carapace Length (in $\mathrm{cm}$. ) & References \\
\hline J. russelli & Saskatchewan, Canada & $\begin{array}{c}\text { Ravenscrag Fm. } \\
\text { Late Cretaceous } \\
\text { (Late Maastrichtian) }\end{array}$ & 50 & [63] \\
\hline J. backmani & Montana, USA & $\begin{array}{l}\text { Clarkforkian } 1 \\
\text { Late Paleocene }\end{array}$ & 70 & {$[31]$} \\
\hline Sinemys lens & $\begin{array}{l}\text { Xintai, Shandong, } \\
\text { China }\end{array}$ & $\begin{array}{l}\text { Mengyin Fm. } \\
\text { Early Cretaceous }\end{array}$ & 19.2 & [76] \\
\hline $\begin{array}{c}\text { S. gamera (including } S . \\
\text { chabuensis) }\end{array}$ & $\begin{array}{l}\text { Ordos Basin, Inner } \\
\text { Mongolia, China }\end{array}$ & $\begin{array}{l}\text { Luohandong Fm. and } \\
\text { Jingchuan Fm. } \\
\text { Early Cretaceous }\end{array}$ & 14.3 & {$[60,61]$} \\
\hline S. brevispinus & $\begin{array}{l}\text { Ordos Basin, Inner } \\
\text { Mongolia, China }\end{array}$ & $\begin{array}{l}\text { Jingchuan Fm. } \\
\text { Early Cretaceous }\end{array}$ & 21 & [37] \\
\hline Hoyasemys jimenezi & Cuenca, Spain & $\begin{array}{c}\text { Caliza de la Huérguina } \\
\text { Fm. Barremian }\end{array}$ & 6.1 & [12] \\
\hline Gallica lapparentiana & Paris Basin, France & Late Paleocene (Thanetian) & 50 & [11] \\
\hline
\end{tabular}

\section{Turtles from the Phu Kradung Formation and Their Implications for the Age of the Formation}

The Phu Kradung Formation is the basal unit of the Khorat Group [22,77]. Although it is now generally accepted that the formations of the Khorat Group above the Phu Kradung Formation (Phra Wihan, Sao Khua, Phu Phan, and Khok Kruat Formations in ascending order) are Early Cretaceous in age, the age of the Phu Kradung Formation is still uncertain. The evidence from vertebrate paleontology, notably dinosaurs, supports a Late Jurassic age for that formation, whereas palynology and detrital zircon thermochronology suggest an Early Cretaceous age [25,26,78,79].

The Phu Kradung Formation contains two distinct turtle assemblages. The lower part of the formation has yielded the small xinjiangchelyids, Phunoichelys thirakhupti and Kalasinemys prasarttongosothi $[18,19]$. Numerous specimens of these two taxa have been unearthed from the Phu Noi site, and their fragmentary remains have also been collected from Ban Khok Sanam locality, Kalasin Province [80]. Kalasinemys, based on the associated skull and shell material, is particularly close to Annemys known from the Late Jurassic of northern China and Mongolia [7,18,81,82]. Xinjiangchelyids are the dominant turtle group in the Middle-Late Jurassic of China and Central Asia. Abundant remains of this group have been recorded from the Sichuan Basin and Yunnan Province, SW China, Junggar and Turfan basins in northern China, and also from Mongolia and Kyrgyzstan $[1,2,73,74,81-84]$. Therefore, the composition of the turtle assemblage and its close affinity with the turtle faunas from China and Central Asia seem to support a Late Jurassic age for the lower part of the Phu Kradung Formation.

The turtle fauna from the upper part of the Phu Kradung Formation shows a remarkable change compared with that from the lower part. In this part of the formation, the remains of a large, possible stem trionychoid turtle, Basilochelys macrobios, are common. They have been collected from numerous localities in Mukdahan Province, and also from Nong Bua Lamphu and Kalasin Provinces [5,72]. The predominance of the trionychoids in the turtle assemblages from the upper part of the Phu Kadung Formation is more comparable to what is observed in the younger formations of the Khorat Group, e.g., the Early Cretaceous Sao Khua and Khok Kruat Formations which have hitherto yielded only trionychoids $[5,85,86]$.

The discovery of Yakemys, a Macrobaenidae from the upper part of the Phu Kradung Formation, together with Basilochelys, provides further support for an Early Cretaceous age for that part of the formation. Macrobaenids are dominant in the turtle faunas from 
the Early Cretaceous in Asia; they are particularly well represented in the Jehol Biota (NE China), whereas their record in the Jurassic is scanty. Hongkongochelys yehi from the Shangshaximiao Formation, Sichuan Basin is a rare instance of that group from the Late Jurassic [64]. The composition of the turtle fauna from the upper part of the Phu Kradung Formation consisting of stem trionychoids and macrobaenids is comparable to that from the Jehol Biota, although the proportions of these two groups are different: trionychoids are dominant on the Khorat Plateau and macrobaenids are dominant in the Jehol Biota.

To sum up, the turnover of the turtle faunas on the Khorat Plateau, marked also in more northern parts of Asia between the Jurassic and Cretaceous turtle faunas, occurred within the Phu Kradung Formation. The evidence from the turtle assemblages seems to support a Late Jurassic age for the lower part of the formation and an Early Cretaceous age for its upper part. This is somewhat in agreement with the evidence from palynological research which indicates that a Late Jurassic age cannot be excluded for the lowermost part of the Phu Kradung Formation because of the absence of the key Early Cretaceous marker taxa [25]. The faunal turnover within the Phu Kradung Formation is also marked for crocodiles, and the upper part of the formation is characterized by the pholidosaurids, whereas teleosaurids are dominant in the lower part [87].

It is noteworthy that the upper part of the Phu Kradung Formation is basal Cretaceous (Berriasian-?Valanginian [77]) in age, probably older than the deposits of the Jehol Biota which are now considered as Barremian-Aptian in age [88], but possibly closer stratigraphically to the Mengyin Formation of Shandong and the Luohandong Formation of the Ordos Basin in Inner Mongolia, China. The Mengyin Formation, previously considered as Late Jurassic by some authors (e.g., [89]), has been recently dated using detrital zircons as 145-136 Ma, corresponding to the Berriasian-lower Valanginian [90]. The turtle assemblage from the Mengyin Formation is composed of the macrobaenids Sinemys lens and Ordosemys leios, and a sinochelyid Sinochelys applanata $[57,60,76]$. On the basis of its vertebrate assemblage, the Luohandong Formation, which has also yielded Ordosemys leios and a Sinemys (S. gamera), is correlated with the Mengyin Formation $[55,57,60]$. The Sinemys-Ordosemys assemblage seems to be typical of the basal Cretaceous formations such as the Mengyin and Luohandong Formations. Sinemys is also recorded from the Jingchuan Formation that conformably overlies the Luohandong Formation but is absent from the younger Jehol Biota $[37,61]$. It has been suggested that the lack of Sinemys in the lacustrine Jehol Biota is due to environmental differences, since Sinemys lived in a more dynamic habitat (e.g., the river systems [37]). With the more accurate geological dating, and correlations available now, the age difference should also be taken into consideration.

\section{Conclusions}

Yakemys multiporcata n. g. n. sp. represents one of the earliest Macrobaenidae hitherto known, and this finding extends the paleogeographical distribution of the group to SE Asia. The discovery of a macrobaenid turtle in Thailand provides further support for the Early Cretaceous age of the upper part of the Phu Kradung Formation and the new evidence of faunal exchange between the SE Asia and more northern parts of mainland Asia at the very beginning of the Cretaceous. Yakemys multiporcata commonly occurs together with Basilochelys macrobios, although both turtles were likely aquatic animals as indicated by their low shell; the different morphology of the shell, especially the plastron, suggests that these turtles had different modes of life. Further discovery of more complete material, especially skull and limb bones, is expected for a better understanding of the phylogenetic relationships and the lifestyle of this strange turtle.

Supplementary Materials: The following are available online at https:/ /www.mdpi.com/article/ 10.3390/d13120630/s1, Supplementary S1: Character list and dataset, Supplementary S2: Simplified strict consensus cladogram obtained from the constrained phylogenetic analysis, Supplementary S3: Complete strict (above) and Adams (below) consensus cladograms. 
Author Contributions: Conceptualization, H.T. and J.C.; methodology, H.T. and J.C.; software, J.C.; validation, H.T., P.C., W.N., P.D., S.S., E.B., V.S., K.W., U.D. and J.C.; formal analysis, H.T. and J.C.; investigation, H.T., P.C., W.N., P.D., S.S., E.B., V.S., K.W., U.D. and J.C.; resources, P.C., P.D., S.S., V.S. and K.W.; data curation, H.T. and J.C.; writing-original draft preparation, H.T. and J.C.; writingreview and editing, H.T., J.C. and E.B.; visualization, H.T. and J.C.; supervision, H.T. and J.C.; project administration, P.C. and V.S.; funding acquisition, H.T., E.B., J.C., P.C., S.S. and V.S. All authors have read and agreed to the published version of the manuscript.

Funding: This research was funded by a grant from the International Research Group PalBioDivASE (IRN) grant of CNRS, and the Mahasarakham University Development Fund and the Mahasarakham University (PRC) research grant of the fiscal year 2020.

Institutional Review Board Statement: Not applicable.

Data Availability Statement: Not applicable.

Acknowledgments: This work was supported by a grant from the International Research Group PalBioDivASE (IRN) grant of CNRS, and the Mahasarakham University Development Fund and the Mahasarakham University (PRC) research grant of the fiscal year 2020. We thank the members and students of the Palaeontological Research and Education Centre (PRC), Mahasarakham University and Department of Mineral Resources (DMR) who took part in the field work.

Conflicts of Interest: We declare no conflicts of interest.

\section{References}

1. Sukhanov, V.B. Mesozoic turtles of middle and central Asia. In The Age of Dinosaurs in Russia and Mongolia; Benton, M.J., Shishkin, M.A., Unwin, D.M., Kurochkin, E.N., Eds.; Cambridge University Press: Cambridge, UK, 2000; pp. $309-367$.

2. Tong, H.; Danilov, I.; Ye, Y.; Ouyang, H.; Peng, G.; Li, K. A Revision of Xinjiangchelyid Turtles from the Late Jurassic of Sichuan Basin, China. Ann. Paléontologie 2012, 98, 73-114. [CrossRef]

3. Tong, H.; Li, L.; Ouyang, H. A Revision of Sinaspideretes wimani Young \& Chow, 1953 (Testudines: Cryptodira: Trionychoidae) from the Jurassic of the Sichuan Basin, China. Geol. Mag. 2014, 151, 600-610.

4. Joyce, W.G.; Rabi, M.; Clark, J.M.; Xu, X. A Toothed Turtle from the Late Jurassic of China and the Global Biogeographic History of Turtles. BMC Evol. Biol. 2016, 16, 236. [CrossRef]

5. Tong, H.; Claude, J.; Suteethorn, V.; Naksri, W.; Buffetaut, E. Turtle assemblages of the Khorat Group (Late Jurassic-Early Cretaceous) of NE Thailand and their palaeobiogeographical significance. In Late Palaeozoic and Mesozoic Continental Ecosystems in SE Asia; Buffetaut, E., Cuny, G., Le Loeuff, J., Suteethorn, V., Eds.; Geological Society, Special Publication: London, UK, 2009; Volume 315, pp. 141-152.

6. Tong, H.; Danilov, I.; Ye, Y.; Ouyang, H.; Peng, G. Middle Jurassic Turtles from the Sichuan Basin, China: A Review. Geol. Mag. 2012, 149, 675-695. [CrossRef]

7. Rabi, M.; Sukhanov, V.B.; Egorova, V.N.; Danilov, I.; Joyce, W.G. Osteology, Relationships, and Ecology of Annemys (Testudines, Eucryptodira) from the Late Jurassic of Shar Teg, Mongolia, and Phylogenetic Definitions for Xinjiangchelyidae, Sinemydidae, and Macrobaenidae. J. Vertebr. Paleontol. 2014, 34, 327-352. [CrossRef]

8. Tong, H. Testudines. In Parareptilians, Captorhines and Testudines; Li, J., Tong, H., Eds.; Palaeovertebrata Sinica; Science Press: Beijing, China, 2017; Volume 2, pp. 92-365.

9. Danilov, I.G.; Syromyatnikova, E.V.; Sukhanov, V.B. Subclass Testudinata. In Fossil Vertebrates of Russia and Adjacent Countries. Fossil Reptiles and Birds. Part 4; Lopatin, A.V., Zelenkov, N.V., Eds.; GEOS: Moscow, Russia, 2017; pp. $27-395$.

10. Vandermark, D.; Tarduno, J.A.; Brinkman, D.B.; Cottrell, R.D.; Mason, S. New Late Cretaceous Macrobaenid Turtle with Asian Affinities from the High Canadian Arctic: Dispersal via Ice-Free Polar Routes. Geology 2009, 37, 183-186. [CrossRef]

11. Pérez-García, A. A European Cenozoic Macrobaenid: New Data about the Paleocene Arrival of Several Turtle Lineages to Europe. J. Vertebr. Paleontol. 2020, 40, e1795874. [CrossRef]

12. Pérez-García, A.; Marcelo, S.; Ortega, F. A New Freshwater Basal Eucryptodiran Turtle from the Early Cretaceous of Spain. Acta Palaeontol. Pol. 2012, 57, 285-298. [CrossRef]

13. Lee, Y.-N.; Hutchison, J.H.; Chang, K.-H. The First Mesozoic Turtle from South Korea. Cretac. Res. 2009, 30, 1287-1292. [CrossRef]

14. Hirayama, R. Review of Fossil Turtles of Japan. Fossils 2006, 47-59.

15. Hirayama, R.; Brinkman, D.B.; Danilov, I.G. Distribution and Biogeography of Non-Marine Cretaceous Turtles. Russ. J. Herpetol. 2000, 7, 181-198.

16. Hirayama, R. Preliminary Report of the Fossil Turtles from the Kitadani Formation (Early Cretaceous) of the Tetori Group of Katsuyama, Fukui Prefecture, Central Japan. Mem. Fukui Prefect. Dinosaur. Mus. 2002, 1, $29-40$.

17. Hirayama, R. Fossil turtles. In Fossils of Kuwajima Kaseki-Kabe (Fossil-Bluff), Scientific Report on a Neocomian (Early Cretaceous) Fossil Assemblage from the Kuwajima Formation; Tetori Group: Shiramine, Japan, 2000; pp. 75-92. 
18. Tong, H.; Naksri, W.; Buffetaut, E.; Suteethorn, S.; Suteethorn, V.; Chantasit, P.; Claude, J. Kalasinemys, a New Xinjiangchelyid Turtle from the Late Jurassic of NE Thailand. Geol. Mag. 2019, 147, 1645-1656. [CrossRef]

19. Tong, H.; Naksri, W.; Buffetaut, E.; Suteethorn, V.; Suteethorn, S.; Deesri, U.; Sila, S.; Chanthasit, P.; Claude, J. A New Primitive Eucryptodiran Turtle from the Upper Jurassic Phu Kradung Formation of the Khorat Plateau, NE Thailand. Geol. Mag. 2015, 152, 166-175. [CrossRef]

20. Bumrungsong, P.; Yamunsabideen, N. Geologic Map of Changwat Kalasin, Scale 1:250,000; Department of Mineral Resources: Bangkok, Thailand, 2009. (In Thai)

21. Meesook, A. Jurassic-Cretaceous Environment of the Northeastern Thailand: Geological Survey Division; Department of Mineral Resources: Bangkok, Thailand, 2001; pp. 1-43.

22. Racey, A.; Love, M.A.; Canham, A.C.; Goodall, J.G.S.; Polachan, S.; Jones, P.D. Stratigraphy and Reservoir Potential of the Mesozoic Khorat Group, NE Thailand: Part 1: Stratigraphy and Sedimentary Evolution. J. Pet. Geol. 1996, 19, 5-39. [CrossRef]

23. Sattayarak, N. Review of the Continental Mesozoic Stratigraphy of Thailand. In Proceedings of the Workshop on Stratigraphic Correlation of Thailand and Malaysia, Bangkok, Thailand, 1 January 1983; pp. 127-148.

24. Ward, D.E.; Bunnag, D. Stratigraphy of the Mesozoic Khorat Group in Northeastern Thailand; Department of Mineral Resources: Bangkok, Thailand, 1964.

25. Racey, A.; Goodall, J.G. Palynology and stratigraphy of the Mesozoic Khorat Group red bed sequences from Thailand. In Late Palaeozoic and Mesozoic Continental Ecosystems in SE Asia; Buffetaut, E., Cuny, G., Le Loeuff, J., Suteethorn, V., Eds.; Geological Society, Special Publication: London, UK, 2009; Volume 315, pp. 69-83.

26. Carter, A.; Bristow, C.S. Linking Hinterland Evolution and Continental Basin Sedimentation by Using Detrital Zircon Thermochronology: A Study of the Khorat Plateau Basin, Eastern Thailand. Basin Res. 2003, 15, 271-285. [CrossRef]

27. Tong, H.; Ji, S.-A.; Ji, Q. Ordosemys (Testudines: Cryptodira) from the Yixian Formation of Liaoning Province, Northeastern China: New Specimens and Systematic Revision. Am. Mus. Novit. 2004, 3438, 1-20. [CrossRef]

28. Sukhanov, V.B. Subclass Testudinata, Testudinates. In Fundamentals of Palaeontology Amphibians, Reptiles and Birds; Orlov, J.A., Ed.; GEOS: Moscow, Russia, 1964. (In Russian)

29. Danilov, I.G. Kirgizemys (Testudines, Macrobaenidae): New Material from the Lower Cretaceous of Buryatia (Russia) and Taxonomic Revision. Russ. J. Herpetol. 2006, 13, 46-62.

30. Danilov, I.G.; Parham, J.F. The Type Series of Sinemys wuerhoensis, a Problematic Turtle from the Lower Cretaceous of China, Includes at Least Three Taxa. Palaeontology 2007, 50, 431-444. [CrossRef]

31. Brinkman, D.B.; Densmore, M.J.; Joyce, W.G. Macrobaenidae (Testudines: Eucryptodira) from the Late Paleocene (Clarkforkian) of Montana and the Taxonomic Treatment of Clemmys backmani. Bull. Peabody Mus. Nat. Hist. 2010, 51, 147-156. [CrossRef]

32. Brinkman, D.B.; Yuan, C.-X.; Ji, Q.; Li, D.-Q.; You, H.-L. A New Turtle from the Xiagou Formation (Early Cretaceous) of Changma Basin, Gansu Province, PR China. Palaeobiodivers. Palaeoenviron. 2013, 93, 367-382. [CrossRef]

33. Gaffney, E.S.; Ye, X. Dracochelys: A New Cryptodiran Turtle from the Early Cretaceous of China. Am. Mus. Novit. 1992, 3048, $1-20$.

34. Ye, H.-K. Fossil Turtles of China. Palaeontol. Sin. 1963, 150, 1-112.

35. Chkhikvadze, V.M. The Fossil Turtles of the Family Sinemydidae. Akad. Nauk Gruz. SSR Izv. Ser. Biol. 1976, 3, $265-270$.

36. Khosatzky, L.I.; Nessov, L.A. Large Turtles of the Late Cretaceous of Middle Asia. Tr. Zool. Inst. AN SSSR 1979, 89, 98-108.

37. Tong, H.; Brinkman, D. A New Species of Sinemys (Testudines: Cryptodira: Sinemydidae) from the Early Cretaceous of Inner Mongolia, China. Palaeobiodivers. Palaeoenviron. 2013, 93, 355-366. [CrossRef]

38. Zhou, C.-F.; Rabi, M. A Sinemydid Turtle from the Jehol Biota Provides Insights into the Basal Divergence of Crown Turtles. Sci. Rep. 2015, 5, 16299. [CrossRef]

39. Cadena, E.; Parham, J. Oldest Known Marine Turtle? A New Protostegid from the Lower Cretaceous of Colombia. PaleoBios 2015, 32, 1-42. [CrossRef]

40. Rabi, M.; Zhou, C.-F.; Wings, O.; Ge, S.; Joyce, W.G. A New Xinjiangchelyid Turtle from the Middle Jurassic of Xinjiang, China and the Evolution of the Basipterygoid Process in Mesozoic Turtles. BMC Evol. Biol. 2013, 13, 203. [CrossRef]

41. Joyce, W.G.; Anquetin, J.; Cadena, E.-A.; Claude, J.; Danilov, I.G.; Evers, S.W.; Ferreira, G.S.; Gentry, A.D.; Georgalis, G.L.; Lyson, T.R. A Nomenclature for Fossil and Living Turtles Using Phylogenetically Defined Clade Names. Swiss J. Palaeontol. 2021, 140, 1-45. [CrossRef]

42. Pérez-García, A.; Codrea, V. New Insights on the Anatomy and Systematics of Kallokibotion Nopcsa, 1923, the Enigmatic Uppermost Cretaceous Basal Turtle (Stem Testudines) from Transylvania. Zool. J. Linn. Soc. 2018, 182, 419-443. [CrossRef]

43. Pérez-García, A. Surviving the Cretaceous-Paleogene Mass Extinction Event: A Terrestrial Stem Turtle in the Cenozoic of Laurasia. Sci. Rep. 2020, 10, 1-13. [CrossRef]

44. Joyce, W.G.; Rollot, Y. An Alternative Interpretation of Peltochelys duchastelii as a Paracryptodire. Fossil Record 2020, $23,83-93$. [CrossRef]

45. Tatarinov, L.P. A New Turtle of the Family Baenidae from the Lower Eocene of Mongolia. Paleontol. Zhurnal 1959, 1, $100-113$.

46. Sukhanov, V.B.; Narmandakh, P. Paleocene Turtles of Mongolia. Tr. Sovmest. Sov.-Mong. Paleontol. Ekspeditsii 1976, 3, 107-133.

47. Evers, S.W.; Rollot, Y.; Joyce, W.G. Cranial Osteology of the Early Cretaceous Turtle Pleurosternon bullockii (Paracryptodira: Pleurosternidae). PeerJ 2020, 8, e9454. [CrossRef] 
48. Swofford, D.L. Paup*. Phylogenetic Analysis Using Parsimony (*and Other Methods); Version 4.0; Sinauer: Sunderland, MA, USA, 1998.

49. Thomson, R.C.; Spinks, P.Q.; Shaffer, H.B. A Global Phylogeny of Turtles Reveals a Burst of Climate-Associated Diversification on Continental Margins. Proc. Natl. Acad. Sci. USA 2021, 118, 1-10. [CrossRef] [PubMed]

50. Endo, R.; Shikama, T. Mesozoic Reptilian Fauna in the Jehol Mountainland, Manchoukuo. Bull. Cent. Natl. Mus. Manchoukuo 1942, 3, 1-19.

51. Zhou, C.-F. A Second Specimen of Manchurochelys manchoukuoensis Endo \& Shikama, 1942 (Testudines: Eucryptodira) from the Early Cretaceous Yixian Formation of Western Liaoning, China. Zootaxa 2010, 2534, 57-66.

52. Zhou, C.-F.; Rabi, M.; Joyce, W.G. A New Specimen of Manchurochelys manchoukuoensis from the Early Cretaceous Jehol Biota of Chifeng, Inner Mongolia, China and the Phylogeny of Cretaceous Basal Eucryptodiran Turtles. BMC Evol. Biol. 2014, 14, 77. [CrossRef]

53. Li, L.; Zhou, C.-F.; Rabi, M. The Skeletal Anatomy of Manchurochelys manchoukuoensis (Pan-Cryptodira: Sinemydidae) from the Lower Cretaceous Yixian Formation. Hist. Biol. 2021, 1-17. [CrossRef]

54. Brinkman, D.B. New Material of Dracochelys (Eucryptodira: Sinemydidae) from the Junggar Basin, Xinjiang, Peoples Republic of China. Can. J. Earth Sci. 2001, 38, 1645-1651. [CrossRef]

55. Brinkman, D.B.; Peng, J.-H. Ordosemys leios, n. Gen., n. Sp., a New Turtle from the Early Cretaceous of the Ordos Basin, Inner Mongolia. Can. J. Earth Sci. 1993, 30, 2128-2138. [CrossRef]

56. Ma, Z.L. Mesozoic Turtle Fossil from Donghai Coal Mine of Jixi, Heilongjiang Province. Mus. Res. 1986, 14, 109-112.

57. Li, D.-Q.; Zhou, C.-F.; Li, L.; Yang, J.-T.; Li, L.; Rabi, M. The Sinemydid Turtle Ordosemys from the Lower Cretaceous Mengyin Formation of Shandong, China and Its Implication for the Age of the Luohandong Formation of the Ordos Basin. PeerJ 2019, 7, e6229. [CrossRef]

58. Zhou, C.-F.; Wu, W.-H.; Rabi, M. Presence of the Jehol Biota Turtle Ordosemys liaoxiensis in the Early Cretaceous Hengtongshan Formation of Southern Jilin Province, China. Foss. Rec. 2019, 22, 57-64. [CrossRef]

59. Zhou, C.-F. A New Eucryptodiran Turtle from the Early Cretaceous Jiufotang Formation of Western Liaoning, China. Zootaxa 2010, 2676, 45-56. [CrossRef]

60. Brinkman, D.B.; Peng, J.-H. New Material of Sinemys (Testudines, Sinemydidae) from the Early Cretaceous of China. Can. J. Earth Sci. 1993, 30, 2139-2152. [CrossRef]

61. Ji, S.-A.; Chen, X.-Y. A New Early Cretaceous Turtle from Otog Qi, Inner Mongolia, China. Acta Geol. Sin. $2018,92,629-637$.

62. Parham, J.F.; Hutchison, J.H. A New Eucryptodiran Turtle from the Late Cretaceous of North America (Dinosaur Provincial Park, Alberta, Canada). J. Vertebr. Paleontol. 2003, 23, 783-798. [CrossRef]

63. Brinkman, D.B. Judithemys russelli sp. nov., a new macrobaenid turtle from the Late Cretaceous of Saskatchewan, Canada. In All Animals Are Interesting: A Festschrift in Honour of Anthony, P., Russell; Bininda-Emonds, O.R.P., Powell, G.L., Jamniczky, H.A., Bauer, A.M., Theodor, J., Eds.; BIS Verlag: Oldenburg, Germany, 2015; pp. 107-119.

64. Ye, Y. A New Genus of Sinemydidae from the Late Jurassic of Neijiang, Sichuan. Vertebr. PalAsiatica 1999, $37,81-87$.

65. Matzke, A.T.; Maisch, M.W.; Pfretzschner, H.U.; Sun, G.; Stohr, H. A New Basal Sinemydid Turtle (Reptilia: Testudines) from the Lower Cretaceous Tugulu Group of the Junggar Basin (NW China). Neues Jahrb. Geol. Palaontol.-Mon. 2004, 3, 151-167. [CrossRef] [PubMed]

66. Matzke, A.T.; Maisch, M.W. New Information and Specimens of Wuguia hutubeiensis (Reptilia: Testudines) from the Lower Cretaceous Tugulu Group of the Southern Junggar Basin (NW China). Neues Jahrb. Geol. Palaontol.-Mon. 2004, 8, 473-495. [CrossRef] [PubMed]

67. Danilov, I.G.; Sukhanov, V.B. A Basal Eucryptodiran Turtle Sinemys efremovi [Waguia Efremovi] from the Early Cretaceous of China. Acta Palaeontol. Pol. 2006, 51, 105-110.

68. Bohlin, B. Fossil Reptiles from Mongolia and Kansu; Statens Etnografiska Museum: Stockholm, Sweden, 1953.

69. Shao, S.; Li, L.; Yang, Y.; Zhou, C.-F. Hyperphalangy in a New Sinemydid Turtle from the Early Cretaceous Jehol Biota. PeerJ 2018, 6, e5371. [CrossRef]

70. Danilov, I.G.; Obraztsova, E.M.; Syromyatnikova, E.V. Tienfucheloides undatus-A turtle puzzle from the Cenomanian of Uzbekistan. In Proceedings of the Turtle Evolution Symposium, Tokyo, Japan, 19 June 2018; pp. 67-72.

71. Pérez-García, A.; Murelaga, X. Galvechelone lopezmartinezae Gen. et Sp. Nov., a New Cryptodiran Turtle in the Lower Cretaceous of Europe. Palaeontology 2012, 55, 937-944. [CrossRef]

72. Tong, H.; Claude, J.; Naksri, W.; Suteethorn, V.; Buffetaut, E.; Khansubha, S.; Wongko, K.; Yuangdetkla, P. Basilochelys macrobios n. gen. and n. sp., a large cryptodiran turtle from the Phu Kradung Formation (latest Jurassic-earliest Cretaceous) of the Khorat Plateau, NE Thailand. In Late Palaeozoic and Mesozoic Continental Ecosystems in SE Asia; Buffetaut, E., Cuny, G., le Loeuff, J., Suteethorn, V., Eds.; Geological Society, Special Publication: London, UK, 2009; Volume 315, pp. 153-173.

73. Peng, J.-H.; Brinkman, D.B. New Material of Xinjiangchelys (Reptilia: Testudines) from the Late Jurassic Qigu Formation (Shishugou Group) of the Pingfengshan Locality, Junggar Basin, Xinjiang. Can. J. Earth Sci. 1993, 30, 2013-2026. [CrossRef]

74. Tong, H.; Dong, Z.; Wang, T. A Revision of Xinjiangchelys oshanensis (Ye, 1973), and New Material from the Middle Jurassic of Lufeng, Yunnan Province, China. Bull. Société Géologique Fr. 2015, 186, 43-49. [CrossRef]

75. Nessov, L.A. An Archaic Late Cretaceous Turtle from Western Uzbekistan. Paleontol. Zhurnal 1978, 4, $101-105$.

76. Wiman, C.J.J.E. Fossile Schildkröten Aus China. Palaeontol. Sin. 1930, 6, 1-56. 
77. Racey, A. Mesozoic red bed sequences from SE Asia and the significance of the Khorat Group of NE Thailand. In Late Palaeozoic and Mesozoic Continental Ecosystems in SE Asia; Buffetaut, E., Cuny, G., Le Loeuff, J., Suteethorn, V., Eds.; Geological Society, Special Publication: London, UK, 2009; Volume 315, pp. 41-67.

78. Buffetaut, E.; Suteethorn, V.; Tong, H. Dinosaur Assemblages from Thailand: A Comparison with Chinese Faunas. In Proceedings of the Heyuan International Dinosaur Symposium; Lü, J., Kobayashi, Y., Huang, D., Lee, Y.N., Eds.; Geological Publishing House: Beijing, China, 2006; pp. 19-37.

79. Buffetaut, E.; Suteethorn, V. A Sinraptorid Theropod (Dinosauria: Saurischia) from the Phu Kradung Formation of Northeastern Thailand. Bull. Société Géologique Fr. 2007, 178, 497-502. [CrossRef]

80. Tong, H.; Claude, J.; Naksri, W.; Suteethorn, V.; Suteethorn, S.; Chanthasit, P.; Buffetaut, E. Turtle assemblages from the Phu Kradung Formation of the Khorat Group. NE Thailand and their stratigraphical and palaeobiogeographical implications. In Proceedings of the Turtle Evolution Symposium, Tokyo, Japan, 19 June 2018; pp. 56-60.

81. Wings, O.; Rabi, M.; Schneider, J.W.; Schwermann, L.; Sun, G.; Zhou, C.-F.; Joyce, W.G. An Enormous Jurassic Turtle Bone Bed from the Turpan Basin of Xinjiang, China. Naturwissenschaften 2012, 99, 925-935. [CrossRef]

82. Brinkman, D.B.; Eberth, D.A.; Xu, X.; Clark, J.M.; Wu, X.-C. Turtles from the Jurassic Shishugou Formation of the Junggar Basin, Peoples Republic of China, with comments on the basicranial region of basal eucryptodires. In Morphology and Evolution of Turtles; Brinkman, D.B., Holroyd, P.A., Gardner, J.D., Eds.; Springer: Berlin/Heidelberg, Germany, 2013; pp. 147-172.

83. Nessov, L.A. On Some Mesozoic Turtles of the Fergana Depression (Kyrgyzstan) and Dzhungar Alatau Ridge (Kazakhstan). Russ. J. Herpetol. 1995, 2, 134-141.

84. Rabi, M.; Joyce, W.G.; Wings, O. A Review of the Mesozoic Turtles of the Junggar Basin (Xinjiang, Northwest China) and the Paleobiogeography of Jurassic to Early Cretaceous Asian Testudinates. Palaeobiodivers. Palaeoenviron. 2010, 90, 259-273. [CrossRef]

85. Tong, H.; Suteethorn, V.; Claude, J.; Buffetaut, E.; Jintasakul, P. The Turtle Fauna from the Khok Kruat Formation (Early Cretaceous) of Thailand. In Proceedings of the International Conference on Geology, Geotechnology and Mineral Resources of Indochina (GEOINDO 2005); Khon Kaen University: Khon Kaen, Thailand, 2005; pp. 610-614.

86. Tong, H.; Buffetaut, E.; Suteethorn, V. Isanemys, a New Adocid Turtle from the Sao Khua Formation (Early Cretaceous) of the Khorat Plateau, Northeastern Thailand. Foss. Turt. Res. 2006, 1, 128-137.

87. Martin, J.E.; Suteethorn, S.; Lauprasert, K.; Tong, H.; Buffetaut, E.; Liard, R.; Salaviale, C.; Deesri, U.; Suteethorn, V.; Claude, J. A New Freshwater Teleosaurid from the Jurassic of Northeastern Thailand. J. Vertebr. Paleontol. 2019, 38, 6. [CrossRef]

88. Pan, Y.; Sha, J.; Zhou, Z.; Fürsich, F.T. The Jehol Biota: Definition and Distribution of Exceptionally Preserved Relicts of a Continental Early Cretaceous Ecosystem. Cretac. Res. 2013, 44, 30-38. [CrossRef]

89. Dong, Z. Dinosaurian Faunas of China; China Ocean Press: Beijing, China, 1992.

90. Xu, J.; Li, Z. Middle-Late Mesozoic Sedimentary Provenances of the Luxi and Jiaolai Areas: Implications for Tectonic Evolution of the North China Block. J. Asian Earth Sci. 2015, 111, 284-301. [CrossRef] 